\title{
Abilities of Airborne and Space-Borne Sensors for Managing Natural Disasters
}

\author{
Mathias J.P.M. Lemmens \\ Section GIS Technology, OTB Research Institute for Housing, Urban and \\ Mobility Studies, TU Delft, P.O. Box 5030, 2600 GA Delft, \\ the Netherlands. \\ Email: t.lemmens@otb.tudelft.nl
}

\begin{abstract}
Mankind is putting increasing pressure on the one and only Earth his race has to share, not only by sheer numbers but also, unfortunately, wasteful lifestyle. Those numbers and that lifestyle are causing many areas to become rapidly more vulnerable to a wide range of technological, environmental and natural hazards. It is generally agreed that the availability of proper geo-data is crucial for the entire management cycle of disasters. The Geo-information technology community has produced and continues to produce floods of airborne, space-borne and other accurate, timely and detailed data. All these data are well suited as sound foundation for disaster management. The Geo-information technology community has also developed and continues to develop sophisticated technology to process and analyse the data in order for it to arrive at the right information at the right time and to disseminate it to the right persons. The present paper provides backdrops on the abilities of airborne and space-borne sensors for managing natural disasters.
\end{abstract}

\section{Introduction}

Disasters are of all ages. When they strike, more often than not they strike suddenly and ruthlessly. The damage disasters cause fills us with deep awe for the unimaginable forces natural phenomena are able to release. Annual economic loss associated with natural disasters doubled every decade of the last half century. Economic loss resulting from natural hazards even 
tripled in the course of the nineties and now amounts to an annual one million millions Euro. The Christmas 2004 tsunami disaster is unprecedented in terms of the amount of sudden loss of life, injured victims and demolished constructions. However, in terms of economic losses, this natural disaster, which did overwhelmingly affect nearly every coastal zone of the Indian Ocean, seems to be of a quite modest extent. Indeed, the ratio of actual damage and financial losses in the poor regions of the world is much more profound than in the richer ones. This seems to be an unavoidable social phenomenon, notwithstanding its unfairness.

Together with the Yangtze River summer flood of 1998 and the 2001 and 2003 earthquakes hitting Gujarat, India, and Bam, Iran, respectively, the Christmas 2004 tsunami disaster shows that management of natural disasters is urgent and should be given high priority on the international agenda. Disaster management involves many diverse activities. These activities can be grouped into five subsequent stages. The first stage concerns assessment: inventorising the sensitivity of the region to certain types of catastrophes. In this stage the risks and danger for human life and environment are determined. The second stage involves mitigation. When the risks and danger are known, one may start to take provisions to make the region less vulnerable to the occurrence of the catastrophes to which the area is sensitive. Proper land use planning and management, and taking strengthening provisions are the actions to be carried out here. In the third stage - preparedness - planning of emergency aid and development of scenarios and monitoring systems are central together with the establishment of early warning systems.

The urgency of the activities in the above three stages is often hard to understand, because they have to be carried out when the sky is still seemingly cloudless. Nothing has happened yet; there is no urgency to force authorities to put effort into these activities. Given the necessary financial resources and all the other priorities many countries are facing, authorities will thus often feel no drive to come into action. This is apparently different from the fourth and fifth stage. Now, the catastrophe has actually struck. Thus authorities cannot afford to keep their hands crossed; the gravity of the catastrophe creates an obligation to respond rapidly. The fourth stage - response - is the most dramatic stage. The catastrophe caused unthinkable human suffering and environmental damage. Rescue teams will attempt to save lives, injured people will be cured and nursed, and relief will be offered to sufferers by food support and provisional housing. This stage is world news for a few weeks and given high priority by all news stations all over the world. The dramatic images displayed during these days are sometimes all that the general public will remember of the disaster for many years. When the general public has gone back to the 
order of the day, the fifth stage arrives: recovery. In the recovery stage, actions are undertaken so that survivors can, in the foreseeable future, pick up their daily lives again. This stage thus mainly consists of revitalization and reconstruction. Houses are rebuilt; roads and railroads as well as other works of infrastructure are repaired. An important although often neglected part of this stage is strategic development; this means tackling the question of how to prevent the area from future disasters in order to secure a safe and sustainable future. An essential part of this tail stage is thus that it acts as a driving force and fosterer for starting and keeping vivid the initial stage: assessment.

Prior to, during and after a disaster, taking appropriate action is critical. For that the right information should be available at the right time to the right persons. The appropriateness of information depends on:

- the type of disaster one wants to cope with

- which of the above five stages the information is needed for

- the geographical scale of the disaster.

\section{Type of Disaster}

Disaster risks stem from sudden energy release in one of the three basic environmental compartments: air, water and land. Table 1 gives examples of natural events, which may take place in each of these compartments and their consequences. Note that all of the mentioned events may result in one or more consequences as indicated.

\begin{tabular}{|l|l|l|l|}
\hline Air & Water & Land & Consequences \\
\hline Cyclones & Sea Floods & Earthquakes & Loss of human lives \\
\hline Windstorms & River Floods & Volcanic activity & $\begin{array}{l}\text { Epidemiological dis- } \\
\text { eases }\end{array}$ \\
\hline $\begin{array}{l}\text { Lack of rainfall } \\
\text { (drought) }\end{array}$ & Tsunami & $\begin{array}{l}\text { Biological Plagues } \\
\text { (e.g. locusts) }\end{array}$ & $\begin{array}{l}\text { Destruction of build- } \\
\text { ings }\end{array}$ \\
\hline $\begin{array}{l}\text { Abundance of } \\
\text { rainfall (flood) }\end{array}$ & & Forest Fires & Destruction of land \\
\hline & & Land slides & Pollution \\
\hline
\end{tabular}

Table 1. Compartments and examples of natural events

The extent of disasters may vary widely over space and time. 


\subsection{Spatial Extent}

The spatial extent of the effects of a natural phenomenon may vary largely from a local neighborhood to the entire globe. More specifically, the spatial extent of a natural disaster may be of:

- spot size (e.g. volcanic activity)

- local (e.g. earthquakes)

- zonal (e.g. cyclones, sea floods, river floods)

- regional (e.g. drought, forest fires)

- continental (e.g. drought, plagues)

- global (e.g. sea level rising)

Many civilizations all over the world flourish as a result of being located on river deltas. To keep all feet dry in the lowlands, two enemies have to be combated: flood threat from the sea and flood threat from the river(s). On the other hand, water is a vital source of life. To stay on friendly terms with your biggest enemy requires an almost divine level of management. In addition to their preference for residing in river deltas, the human race is also inclined to settle in earthquake-sensitive and volcanic-active areas. To prevent human beings from death or injury early-warning systems have been developed based on advanced geo-information technology. For example, Murai and Araki (2003) developed a new, advanced method for earthquake prediction using GPS network triangles.

\subsection{Temporal Extent}

When considering the temporal extent it is appropriate to distinguish two stages, which correspond to the above pre-disaster stage and post-disaster stage. The first one - the culmination period - involves the pre-disaster period in which the destructive forces are culminated. Some disasters are caused by a slow process of culmination of forces over a longer time (e.g. centuries or millennia). For example for an earthquake the culmination period may take centuries, whilst for a cyclone this period may be counted in terms of weeks. The second stage concerns the occurrence of the event and is determined by the abruptness of energy release. An earthquake may come overnight and the released energy may strike hard, sudden and short. A cyclone may harass a zone over an entire continent for several days.

The three dimensions of appearance - spatial extent, culmination period and abruptness of strike - determine which type(s) of geo-data are the most fit for use. For example volcanic activity has a very small spatial extent and will strike abruptly. To monitor properly a natural phenomenon with these characteristics, permanent observation of the spot is vital. Because 
the spatial extent is of spot size the use of a ground-based station suites the best. Over the last five years ground-based infrared monitoring systems have been designed and tested at several active volcanoes (Harris, et al., 2003). The thermal time series measurements obtained at each of these active volcanoes allow for timing for the onset of eruptive events.

\subsection{Observable Quantities}

The above brings us to an important issue: which observable quantities are essential for arriving at an optimal solution in the most cost-effective way? Such essential parameters should be observable or at least be derivable in a sufficient accurate way from observable quantities by using computer models. For economical reasons, the number of parameters should also be few as possible, preferable just one. For monitoring of volcanic activity, temperature is such an essential observable. Continuously recorded thermal data provide information on the thermal evolution of a volcano. From proper analysis of time series of thermal data important features can be derived such as event frequencies, repose time, ejection velocities and time of event onsets (Harris, et al., 2003). River flood management would benefit a lot when information on the amount of dropped rainfall together with the amount of forecasted rainfall and rate of river water level rise provide information about the risk of flood, and which measures are to be taken to tackle the threat in the best way, such as strengthening of dikes, evacuation or willingly flooding of areas of little economical value in order to save densely populated regions where activities of high economical value take place. Such a scenario requires that in previous stages a bunch of data are collected such as land use and the three-dimensional topography in the format of a Digital Elevation Model (DEMs) of high accuracy and high resolution. Airborne Lidar is a very suited data acquisition technology for the generation of DEMS of river areas, urban conglomerates and coastal zones. It is sometimes underestimated that one of the prerequisites to keep the disaster management system effective is that the database has to be maintained on a permanent or semi-permanent basis.

In addition it is necessary that in the pre-disaster stage, the phenomenon has been understood so well that proper models can be determined and transferred to analytical models, which can be digitally handled by computer. In this modeling process, remotely sensed data play a key role for arriving at an understanding of the physical behavior of disasters. For example, Villegas (2004) reports on using Landsat_TM imagery for understanding the eruption of the Nevado del Ruiz Volcano, Colombia on $13^{\text {th }}$ 
November 1985. With 23,000 people being killed it was the fourth worst volcanic disaster in recorded history.

\section{Sensor Technology}

The last decade has thrown up many changes in the way we collect information of the earth surface. From the technological point of view, the main driving forces behind these changes have been the development of new sensors and the ICT revolution. Examples of such sensors are highresolution airborne and space-borne digital cameras, the Orbiting Positioning Systems (GPS and Glonass), Laser Altimetry (airborne and terrestrial Lidar), and Interferometric SAR, which enable the collection of geo-data with a level of detail, accuracy, automation and collection rate never before seen. The accuracy and level of detail of the geo-data produced by these sensors, not only support the national economy in fields like agriculture, forestry, mining, water and coastal management, marine fisheries and sustainable development, but they are also very useful for disaster management purposes. This progress is accompanied by two other technological revolutions: computer technology and telecommunication in general, and more specifically the rapid growth of the internet and its use. These developments are still rapidly expanding. Table 2 and 3 provide values of the basic features of important space-borne remote sensing observation systems. The choice of a data type or mix of data types heavily depends on the disaster management stage, for which the data is used, and the spatial extent and temporal extent of the disaster type. A geo-data type, of which the importance can hardly be overlooked, is the base-map. The function of a base-map is twofold. First of all the base-map acts as the geometric infrastructure to which all other geo-data sets are referenced in order to match a certain spot or feature in the data set to the proper location in the real world. A second function of the base map is related to its thematic contents. Topography, buildings and so on provide information on the predisaster state of the real world. By comparing the base-map with postdisaster data, an inventory of the damage can be made and decisions on proper actions being taken. The presence of a base-map accompanied by proper use may thus rescue people and save economical valuable goods. It is a general observation that combination of data sets is crucial when examining remotely sensed data. 


\begin{tabular}{|l|l|l|l|l|}
\hline Satellite & GR (pan) & GR (ms) & SS/SW & SR (ms) \\
\hline Aster & - & $\begin{array}{l}\text { VNIR 5m,SWIR } \\
30 \mathrm{~m}, \text { TIR 90m }\end{array}$ & $60 \times 60 \mathrm{~km}$ & VNIR, SWIR, TIR \\
\hline Orbview 3 & $1 \mathrm{~m}$ & $4 \mathrm{~m}$ & $8 \times 8 \mathrm{~km}$ & B, G, R, NIR \\
\hline Quickbird & $61 \mathrm{~cm}$ & $2.45 \mathrm{~m}$ & $16.5 \mathrm{~km}$ & $\mathrm{~B}, \mathrm{G}, \mathrm{R}$, NIR \\
\hline SPOT 2 \& 4 & $10 \mathrm{~m}$ & $20 \mathrm{~m}$ & $60 \times 60 \mathrm{~km}$ & $\mathrm{G}, \mathrm{R}, \mathrm{NIR}$, SWIR \\
\hline SPOT 5 & $2,5 \mathrm{~m} \& 5 \mathrm{~m}$ & $10 \mathrm{~m}, 20 \mathrm{~m}, 1 \mathrm{~km}$ & $60 \times 60 \mathrm{~km}$ & $\mathrm{G}, \mathrm{R}, \mathrm{NIR}$, SWIR \\
\hline Ikonos & $1 \mathrm{~m}$ & $4 \mathrm{~m}$ & $11.3 \mathrm{~km}$ & $\mathrm{~B}, \mathrm{G}, \mathrm{R}$, NIR \\
\hline Landsat TM & $15 \mathrm{~m}$ & $30 \mathrm{~m}$, TIR 60m & $170 \times 183 \mathrm{~km}$ & 6 bands +TIR \\
\hline $\begin{array}{l}\text { Resourcesat- } \\
\text { 1 LISS IV }\end{array}$ & $5 \mathrm{~m}$ & $5 \mathrm{~m}$ & $23,9 \mathrm{~km}$ & $\mathrm{G}, \mathrm{R}, \mathrm{NIR}, \mathrm{SWIR}$ \\
\hline CBERS 1 & $20 \mathrm{~m}$ & $20 \mathrm{~m}$ & $113 \mathrm{~km}$ & $\mathrm{~B}, \mathrm{G}, \mathrm{R}, \mathrm{NIR}$ \\
\hline
\end{tabular}

Table 2., Spectral and spatial characteristics of important high resolution space borne earth observations sensors. GR: Ground Resolution, pan: panchromatic, ms: multispectral, SS/SW Scene Size or Swath Width, SR: Spectral Resolution, NIR Near-Infrared, SWIR: Short-Wave Infrared, TIR: Thermal Infrared. (Source: GIM International, 2004, vol. 18, nr. 7)

\begin{tabular}{|l|l|l|l|}
\hline Satellite & Nadir RT & Off-nadir RT & Stereo \\
\hline Aster & $16 \mathrm{~d}$ & Var & Y/IT (64s) \\
\hline Orbview 3 & $15 \mathrm{~d}$ & $3 \mathrm{~d}$ & Y/IT+AT \\
\hline Quickbird & $1-3.5 \mathrm{~d}$ & - & Y/IT+AT \\
\hline SPOT 2 \& 4 & $26 \mathrm{~d}$ & $1-3 \mathrm{~d}$ & Y/AT \\
\hline SPOT 5 & $26 \mathrm{~d}$ & $1-3 \mathrm{~d}$ & $\mathrm{Y} / \mathrm{AT}$ \\
\hline Ikonos & - & $3 \mathrm{~d}$ & $\mathrm{Y} / \mathrm{IT}$ \\
\hline Landsat TM & $16 \mathrm{~d}$ & $\mathrm{~N}$ & $\mathrm{~N}$ \\
\hline $\begin{array}{l}\text { Resourcesat-1 } \\
\text { LISS IV }\end{array}$ & $24 \mathrm{~d}$ & $5 \mathrm{~d}$ & $\mathrm{Y} / \mathrm{AT}(5 \mathrm{~d})$ \\
\hline CBERS 1 & $26 \mathrm{~d}$ & $5 \mathrm{~d}$ & $\mathrm{Y} / \mathrm{AT}(5 \mathrm{~d})$ \\
\hline
\end{tabular}

Table 3. Viewing characteristics of important high resolution space-borne earth observations sensors. RT: Revisit Time, IT: In-Track Stereo, AT: Along-Track Stereo. (Source: GIM International, 2004, vol. 18, nr. 7) 


\section{Dissemination to the Right Persons}

The end-users of geo-information in a disaster management context use geo-information commonly occasionally. One will be in general unaware of the special characteristics and limitations of geo-data. The approach of geo-data in terms of quality, which has become a second nature to the surveying and mapping community, is an unknown line of thought for laymen. For this reason, it is not only the delivery of the data set that needs to be at issue but also its proper use by the end-user. As a consequence, part of the product delivery by the analyst should include advisory about its use. A good understanding of the nature and size of errors that may be present in the data set is of essential importance to every user to gain insight into the value of the information derived. Another need involves easily understandable visualizations. Since end-users are operating under superstress the presentation (visualization) of the derived information should be simple and straightforward to understand. End users in an emergency should be able to interpret a map in half a minute. Therefore, analysts should be trained in basic cartographic principles and the most effective visual presentation of quantitative information. Since good communication is crucial, it is proper to state here that presentation is more important than content. Rather than making geo-data available, the analyst should thus take care of an optimal use of the data by the end-user. For that purpose, it is necessary that disaster managers are thoroughly informed on GIS and remote sensing capabilities, without going too deep in technological issues.

\section{Discussion}

GIS analysts are used to process data in a vector environment. Therefore they underestimate the importance of raster data. They use remote sensing data often just as visual backdrop without using the wealth of information present in the digital reflectance values. This is one of the lessons learned after the Twin Tower disaster (Huck and Adams, 2002). The many uses and analytical potential of raster data thus need to be promoted. Wider use should be made of programs specifically designed for the processing and analysis of grid-based remotely sensed data.

Today risk assessment, mitigation, preparedness, response and recovery are of major concern to governments at all levels: national, state, provincial and municipal. Both authorities and disaster managers increasingly 
acknowledge that acting without accurate detailed and timely geoinformation results in human suffering and huge economic loss. Fortunately, today's geo-information technology is able to provide the fundament upon which disaster managers can found their vital decisions. The quality of geo-data should be adjusted to the aim of the application; it should be fit for use. Unfortunately, during the 1990s an invisible disaster has blown through management land. The geo-data providers of the past were mainly restricted to authorative and respectable governmental agencies, which worked on a non-commercial basis. Since the early 1990s the common consent is that geo-information is a commodity like any other good. As a result, governmental organizations have made a significant step back in providing geo-information to citizens and organizations. Privatization and commercialization has brought much geo-data to a diversity of commercial firms, which are not seldom allied to former governmental agencies. The user may buy the geo-data off-the-shelf and the physical delivery of the data set may go via the internet. One of the consequences of this is that the non-central collected data is stored at distributed locations whilst the quality may be heterogeneous. Today professionals, who are manager by training, run surveying and mapping organizations. Irrespective in which direction they gaze they seem to see just one steering parameter: currency, appearing in three manifestations: return of investment, cost-efficiency and profit. From this business-centered approach, which is in many ways a decent approach of doing business, they will grant the company of which the tender shows the lowest production costs not the company which offers the best quality. However, short-term gains may convert in huge loss on the longer run when the use of collected geo-data results in wrong decisions.

Today, countries under development, which were ruled not that far back in history by foreign nations and mapped by them solely for reasons of exploitation, are becoming increasingly aware of the importance of geoinformation for sustainable development purposes. On $27^{\text {th }}$ September 2004 Nigeria launched its first earth observation satellite. The microsatellite, weighting $100 \mathrm{~kg}$, provides every five days images with a spatial resolution of $32 \mathrm{~m}$ and a spectral resolution of three bands. Notwithstanding this noteworthy achievement, rulers of countries often still do think in military and exploitation terms. During the NigeriaSat-1 workshop, recently held in Abuja, participants recognized that the federal government shows little obligation to provide funding and political support to a national space program (Kofoniyi, 2004). Indeed, it happens too often that governments consider geo-information primarily as a strategic means for consolidation of own power. Consequently, they keep geo-information out of the hands of managers in the private and public sector, frustrating those 
who have in mind the well-being of the country over a period of time which exceeds greatly own live span. Within this context it is also important to note that Geo-information should be made available free of charge in the framework of disaster management.

\section{Conclusions}

Without information human is living in blindness. Without knowledge the ripen outcome of processed information - the sum of all human activities and actions becomes nothing more than null and void. According to the United Nations, the global community is facing a critical challenge with respect to disaster management: "How to better anticipate - and then manage and reduce - disaster risk by integrating the potential threat into its planning and policies?" Geo-information technology has a vital role to play in this challenge. Today, given the abilities of the available technology, a proper approach of disaster management has become mainly a matter of willingness and prioritizing rather than of technology.

\section{References}

Harris A et al (2003) Ground-based infrared monitoring provides new tool for remote tracking of volcanic activity, Eos, vol 84, no 40, pp 409-424

Huck CK, Adams BJ (2002) Emergency response in the wake of the World Trade Center Attack: the Remote sensing Perspective, MCEER Special Report Series, Volume 3, MCEER, Buffalo, New York

Kofoniyi O (2004) NigeriaSat-1 Satellite National Workshop, GIM International, vol 18 , no 12 , pp 55-57

Murrai S, Araki H (2003) Earthquake prediction using GPS: a new method based on GPS network triangles, GIM International, vol 17, no 10, pp 34-37

Stevens D (2005) Emergency response satellite imagery in developing countries: Space-based technologies for disaster management, GIM International, vol 19, no 2

Villegas H (2004) Volcanic disaster seen from space: understanding eruptions using Landsat-TM, GIM International, vol 18, no 5, pp 68-71 